\title{
THE CURRENT STATUS OF THE CANADIAN HOME FITNESS TEST
}

\author{
ROY J. SHEPHARD, MD(Lond), PhD
}

\author{
Director, School of Physical \& Health Education, and \\ Professor of Applied Physiology. \\ Department of Preventive Medicine and Biostatistics, \\ University of Toronto
}

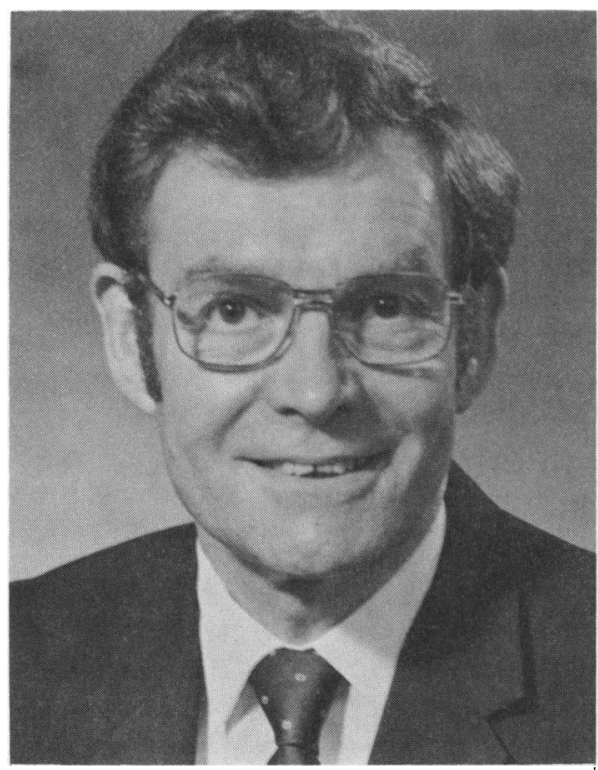

\begin{abstract}
The current status of the Canadian Home Fitness Test is reviewed. This simple procedure was originally conceived for the mass testing of fitness levels and for home use as a motivational tool in exercise programmes. The test is carried out on a double 8 inch step (such as a domestic staircase) at an age and sex-specific rhythm set by a long-playing record. Fitness is assessed from a combination of test-duration and the radial or carotid pulse count immediately following exercise. Use of the procedure by upwards of 500,000 Canadians is reviewed in relation to its safety, validity and practicality. To date, there have been no serious complications. In home use, there is inevitably limited precision, although with practice subjects can learn to count their pulse rate and step in time to the music; further, the test seems well received, achieving its prime objective of stimulating an interest in physical activity and endurance fitness. When the procedure is carried out by a paramedical worker, with e.c.g. recording of the exercise heart rate, it provides at least as good an estimate of maximum oxygen intake as other sub-maximal procedures; the main area of current controversy is interpretation of abnormal stress e.c.g. records, and it is suggested this problem could be resolved by the appropriate training and certification of interested family physicians and paramedical workers.
\end{abstract}

\section{RATIONALE}

Physicians in the United States (Cooper, 1970) have repeatedly urged medically-supervised stress tests as a prelude to participation in a personal fitness programme, particularly in adults over the age of 35 years. Accepting the premises (i) that all healthy adults should adopt an exercise programme, and (ii) that the physician conducts the test on an individual basis at a fee of $\$ 100-\$ 150$, it is plain that medically supervised pre-testing would create an excessive (and possibly an unnecessary) burden for pre-paid systems of medical care.

In this context, the need for a home test of physical fitness was identified at a small seminar sponsored by Sports Canada (Toronto, November 1971). The present author discussed at this gathering the possibility of devising a self-administered "fitness indicator". The idea was given impetus by a National Conference on fitness and health (Orban, 1974) held in December 1972. Here, the need for mass fitness-testing of the adult population was considered further in relation to problems of health screening, exercise prescription, and the continuing motivation of subjects for activity programmes. It was agreed that existing individual medically supervised exercise tests, while optimal in terms of both diagnosis and safety, were prohibitively expensive in terms of both manpower and health care delivery costs. The development of a three-tier system of testing was thus proposed. At the simplest level would be a procedure a healthy subject could carry out himself, in his own home, as a guide to exercise prescription and as a continuing source of motivation. The cost of this system would be no more than $\$ 5$ per family, and could be borne by the participant. At a slightly higher level of sophistication would be a test-battery administered by one or more paramedical health professionals; this would be used in community motivation, in employee fitness projects and 
(with appropriate medical cooperation) in health screening. The information obtained would be more precise than yielded by the self-administered test, and might be linked to evaluation of other items such as skinfolds, muscle strength, flexibility, and lung function, as in the Standard Test of Occupational Fitness (Health \& Welfare, Canada, 1979). However, the cost would rise to \$10-15 per individual. In some instances this might be borne by a sponsor, such as the employer. Subjects judged as unsuitable for such testing would (where necessary) be referred for individual medically-supervised stress-tests.

The Canadian Home Fitness Test (CHFT) was thus designed to satisfy the first two of these needs. In the self-administered form, it was conceived as a motivational device (Shephard, et al 1976). In the words of the National Conference of Fitness and Health:

"It is recommended that Recreation Canada develop a safe, simple self-administered fitness test, the purpose of which would be motivational rather than accurately to evaluate fitness. More specifically, the test should be designed for all age groups and fitness levels and should enable each participant to classify himself according to established norms by indicating the desirable levels of fitness to be achieved. The test could form the core of the educational and promotional program"..

The current format includes not only the CHFT itself but a complete motivational package (the "FitKit"). This kit gives instructions for carrying out the CHFT on a domestic staircase, an age and sex-specific rhythm of stepping being set by music on a long-playing gramophone record. The attractive rhythm of the specially-composed music undoubtedly adds to the appeal of the test, as well as increasing the subject's tolerance of the required vigorous work (Kudo, 1974). The personal fitness level is judged from a simple chart, based upon duration of activity and the immediate recovery pulse rate, while a simple booklet and slide-rule (Jetté, 1975; Jetté et al, 1975) allow the subject to translate his score into an appropriate exercise prescription. If the CHFT is used as part of a paramedical test battery, speciallyconstructed stepping benches can accommodate 2-16 subjects at one time, while heart rate is monitored more precisely, using an electrocardiogram $\left(^{\left(C_{5}\right.}\right.$ lead, Shephard, 1977a).

\section{SAFETY}

When first proposed, the CHFT was assailed on grounds of safety. Detailed review of deaths associated with vigorous exercise (Shephard, 1974; ibid, 1975; ibid, 1977) showed that these were extremely rare events in the healthy adult - so rare, indeed, that precise calculations were impossible. One estimate (Shephard, 1976) suggested that if 5 million middle-aged men and womer each performed a six-minute sub-maximum test once p\& year, it would be necessary to wait 16 to 33 years for single critical episode. Given only a $50 \%$ screening-oust of "high risk" individuals by a simple questionnaire, the waiting period for such an event would rise to 33-6. years. Given a fee of $\$ 100$ per test, the cost of individu medical supervision of $5 \times 66$ million tests would be $\$ 3 \$$ billion dollars, and assuming the physician involved had an $80 \%$ success rate for resuscitation, the cost of saving a single life would be over $\$ 41$ billion dollars!

Despite the extremely low likelihood of an emergence several concessions to safety were made in the design the CHFT, as follows:

(1) All subjects for the tests completed a physicat activity readiness questionnaire (PAR-Q, Chisholm et â 1975). Trials of this type of instrument in Saskatoon (Bailey et al, 1974) and Vancouver (Chisholm et $a \not$ 1975) showed that it eliminated at least a half of those subjects in whom exercise would have had an above average risk. A survey of 1,130 subjects in Toronte showed that some $19 \%$ of subjects made positive responses to PAR-Q (Shephard et al, 1979b). Medicat examination indicated 8 candidates unsuitable fơ exercise (all of whom had been identified). The majority of positive responses were related to high blood pressure: 32 of 100 respondents to this question had a diastole pressure $>90 \mathrm{~mm} \mathrm{Hg}$, but there were also 14 hype tensives not identified and 68 false positive response Possibly the individuals had labile hypertension or mig understood a comment from their physician; possib $\overrightarrow{\mathbb{B}}$ the original measurement was not well made. In the several surveys noted, medical rejections for the CHF have ranged from $0.7 \%$ to $15.6 \%$, yet with all degrees of medical stringency the incidence of exercise-induced premature ventricular systoles and ST segmenta depression has been the same as with screening by self administration of the PAR-Q test.

(2) Subjects were asked to do no more than $3.6 \mathrm{~min}$ of sub-maximum exercise, with termination of the test $\phi f$ certain very cautious pulse ceilings $167-70 \%$ of maximum oxygen intake) were exceeded. This is in direct contrast with one popular U.S. field test (Cooper, 1968; ibi势 1970), where 12 minutes of maximum effort ape required.

(3) A progressive test format was adopted. A subjegt commenced by 3 minutes of stepping at a rąfe appropriate for a person 10 years older than himself, ary only progressed to the rate appropriate for his own age ff the heart rate response to the initial "warm-up" was not excessive.

(4) On the recommendation of the Canadian Medicil Association, radial pulse palpation was used in place the easier carotid artery palpation, to avoid all risk of 


\section{TABLE I}

A summary of medical problems encountered in the testing of 10,402 subjects. Based on data of Canadian Public Health Association (Jetté, 1978)

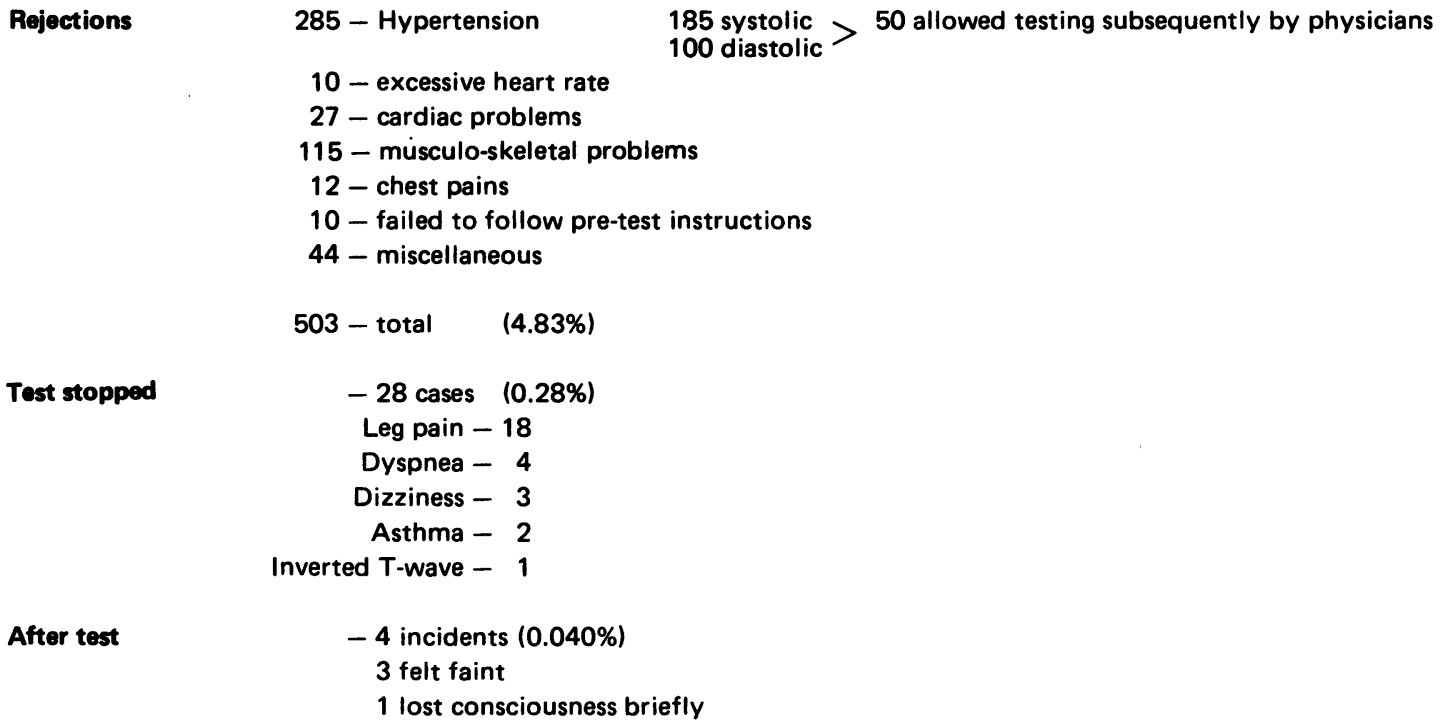

After test

excessive carotid sinus compression. This decision needs review in the light of a recent report showing that the dangers of carotid palpation have been much exaggerated (Gardner et al, 1979).

To date, more than 100,000 copies of the home version of the test have been sold, and it has now been used by an estimated 500,000 subjects, 50,000 under monitored conditions, without a single serious accident. In the first series of 14,794 persons, $3 \%$ were not permitted to take the test for medical reasons (D. Shephard, 1976). Among the 14,312 who completed the test through January 1976, there were only three minor incidents. One man fainted after performing carotid rather than radial palpation. A second man who had answered the PAR-Q test falsely was described as "distressed" during the second stage of the test, while a third who was tired slipped and sprained an ankle. More recently, the Canadian Public Health Association has tested 10,402 workers (Jetté, 1978), again without serious incident (Table I).

\section{CONCEPT}

The CHFT uses the simple and familiar exercise of stepping. The protocol is based on a progressive submaximal test developed by the International Biological Programme (I.B.P., Shephard et al, 1968; Weiner \& Lourie, 1969). Subjects are exercised by ascent and backward descent of a double step, the height being adjusted from the I.B.P. figure of 9 inches per step to 8 inches $(20.3 \mathrm{~cm})$ per step, the latter conforming with a normal domestic step under the Canadian building code. The work rate is based upon the effort tolerance of subjects in Toronto and Saskatoon (Shephard, 1977a) and is designed to elicit $70 \%$ of maximum oxygen intake. A six-pace rhythm is set by age and sex-specific bands of music on a long-playing record or tape-deck (Table II). In a paramedical setting, the heart rate during the final 15 seconds of each exercise bout is taken from an electrocardiograph record or a cardiotachometer. Making the assumption that the body mass has been lifted and lowered with a net mechanical efficiency of $16 \%$ for the six-pace cycle (Shephard, 1967), the maximum oxygen intake can then be estimated, using a computer solution of the Åstrand nomogram (Shephard, 1970, Fig 1), or the nomogram of Jette et al (1975). When the test is self-administered, the long-playing record gives the subject a signal to count his pulse rate during the period 5-15 seconds following each bout of exercise. Performance is then judged from the duration of exercise, $(3,6$ or $9 \mathrm{~min})$ and the pulse count (Table III), using a simplified version of norms derived from a sample of 1,544 adults living in Saskatoon (Bailey et al, 1976). If desired, the subject can also use a small computing wheel to convert the pulse count into an approximate value for his maximum oxygẹn intake (Jetté, 1975).

\section{VALIDATION}

(1) Work rate. The stepping rates corresponding to $70 \%$ of maximum oxygen intake $\left(\mathrm{VO}_{2}\right.$ max) in average test users were estimated originally from the $\mathrm{VO}_{2}(\max )$ 
TABLE II

Basis of the Home Fitness Test (Bailey et al, 1976)

\begin{tabular}{|c|c|c|c|c|c|c|c|}
\hline \multirow[t]{2}{*}{$\begin{array}{l}\text { Age Band } \\
\text { (years) }\end{array}$} & \multicolumn{2}{|c|}{$\begin{array}{l}\text { Anticipated Gross } \\
\mathrm{VO}_{2} \max \\
(\mathrm{ml} \cdot \mathrm{kg} \cdot \mathrm{min})\end{array}$} & \multicolumn{2}{|c|}{$\begin{array}{l}\text { Required rate of climbing } \\
\text { (Ascents per } \mathrm{min} \text { ) } \\
\text { (65-70\% on } 8^{\prime \prime} \text { step) }\end{array}$} & \multicolumn{3}{|c|}{$\begin{array}{l}\text { Corresponding cadence } \\
\text { (Rounded data) } \\
\text { Six beats }\end{array}$} \\
\hline & $M$ & $\mathbf{F}$ & $M$ & $F$ & $M$ & $F$ & \\
\hline Spare band & - & - & - & - & 156 & & 132 \\
\hline $15-19$ & - & - & - & - & 157 & $(144)^{*}$ & 120 \\
\hline $20-29$ & 47 & 38 & 24.2 & 19.1 & 144 & & 114 \\
\hline $30-39$ & 43 & 39 & 21.9 & 19.7 & 132 & & 114 \\
\hline $40-49$ & 38 & 35 & 19.1 & 17.4 & 114 & & 102 \\
\hline $50-59$ & 33 & 30 & 16.3 & 14.6 & 96 & $(102)^{*}$ & 84 \\
\hline $60-69$ & 27 & 24 & 12.9 & 11.2 & 78 & $(84)^{*}$ & $66(84)$ * \\
\hline \multicolumn{8}{|l|}{$\begin{array}{l}\text { warm up for } \\
\text { oldest age }\end{array}$} \\
\hline group & - & - & - & - & 60 & (66) * & $60(66)^{*}$ \\
\hline
\end{tabular}

"To simplify recording, the cadences shown in brackets have been substituted for the theoretically determined values.

Computer Solution of Astrand Nomogram

$\mathrm{VO}_{2}=\frac{6.69 \times(\mathrm{W}, \mathrm{kg}) \times \mathrm{n}+670\left(\mathrm{BSA}, \mathrm{m}^{2}\right)}{5}$

Prediction $\dot{\mathrm{V}} \mathrm{O}_{2}\left\{\frac{195-61}{\mathrm{P}-61}\right\}^{*}$ (Men) $\dot{\mathrm{v}} \mathrm{O}_{2}\left\{\frac{198-72}{P-72}\right\}^{*}$ (Women)
formula

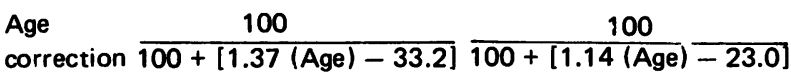

* The formulae actually used in the nomogram are slightly different, namely $193-63 / P-63$ in the men, and $203-73 / P-73$ in the women. However, in the present author's judgement the small modifications adopted here improve the prediction procedure.

Figure 1. A computer solution of the Âstrand nomogram (Shephard, 1970).

of a representative but non-random sample of 661 subjects living in the Toronto area (Shephard, 1977a). The validity of our $\mathrm{VO}_{2}(\max )$ estimates was confirmed when a closer approach to a random sample was obtained by telephone solicitation of 1,544 volunteers in the city of Saskatoon (Bailey et al, 1974).

In order to minimise the required number of bands on the long-playing record, there was some rounding of musical cadences. Nevertheless, Jetté and his colleagues found a good correspondence between the intended and the average measured energy cost of exercise (Fig 2,
TABLE III

Fitness scores, based on duration of stepping and $1 \frac{8}{5}$ second recovery pulse count (Bailey et al, 1976)

$\begin{array}{lll}\begin{array}{l}\text { Age } \\ \text { (Yrs) }\end{array} & \begin{array}{l}\text { First } 3 \text { min } \\ \text { UNDESIRABLE }\end{array} & \begin{array}{l}\text { Second } 3 \text { min } \\ \text { MINIMUM }\end{array} \\ 15-19 & >30 & >27 \\ 20-29 & >29 & >26 \\ 30-39 & >28 & >25 \\ 40-49 & >26 & >24 \\ 50-59 & >25 & >23 \\ 60-69 & >24 & >23\end{array}$

RECOMMENDEQ

1975). One recent report claimed a substantia录 discrepancy between the stated and the actual beat frequency of the music (Cumming and Glenn, 1977 Table IV). This seemed inherently unlikely, since the music had been played on an electronic synthesizer N where it was relatively easy to set and maintain the intended rhythm. Direct recording of the sound on की high-speed chart recorder (Shephard, 1977c) established that the actual frequency was very close to the intendeck value. Presumably, Cumming and Glenn (1977) had problem with a faulty record-player. Some turn-table slow as the playing arm approaches the centre of the disc - this is particularly liable to occur if the record is warped or the needle is worn. Small errors of speed are్టా not serious in home use of the test, but for paramedicaf and scientific purposes we would recommend use of a tape-cassette form of the Fit-Kit. 


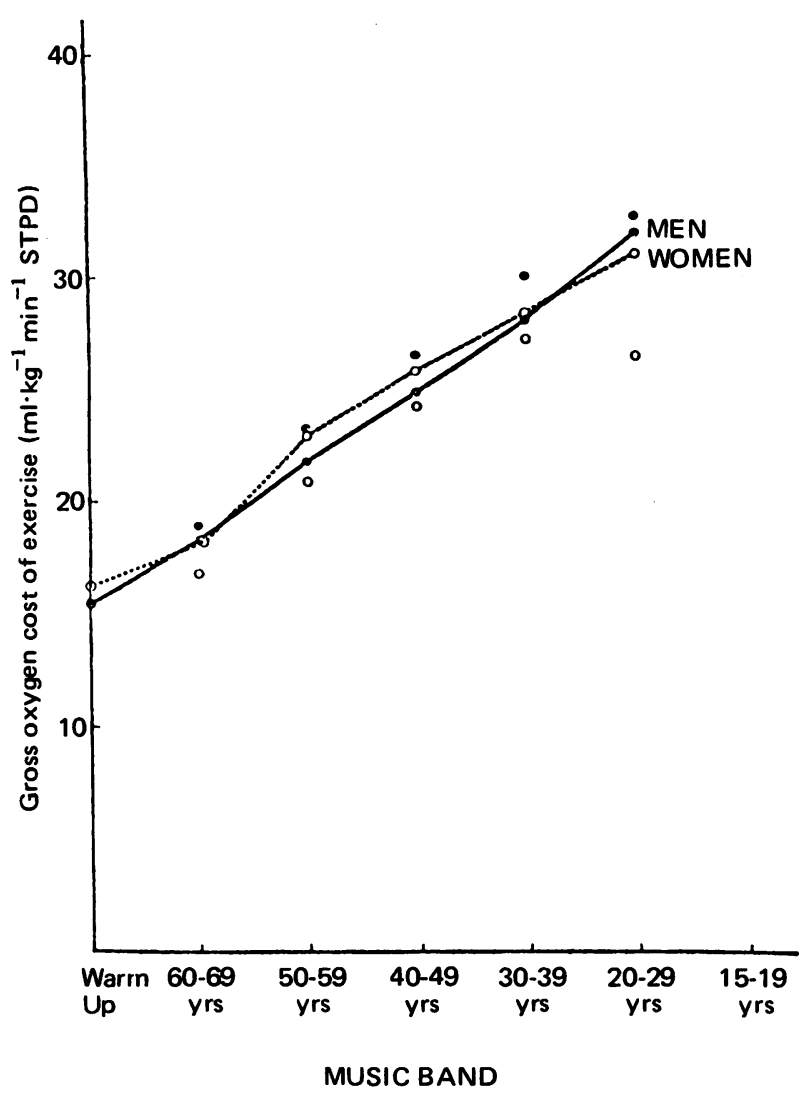

Figure 2. Relationship between intended oxygen cost of stepping (individual points) and observed cost (lines). Based on data of Jetté et al (1975), where young adults performed all 7 stages in sequence.
Errors of stepping rate relative to the music are almost impossible if several subjects perform the test simultaneously. When tests are carried out individually, the average rate of stepping agin conforms closely to the intended value, but one group of investigators (Bonen et al, 1977) found individual deviations of \pm 2 ascents/min about this figure (Table V).

(2) Estimation of $\dot{\mathrm{VO}}_{2}(\max )$. There seems little argument that the supervised form of test with measurement of the exercise heart rate by electrocardiogram gives as valid an estimate of maximum oxygen intake as other sub-maximal test procedures. The original comparison (Bailey et al, 1976) was made with 1,152 adults performing a sub-maximal bicycle ergometer test (Åstrand, 1960). Bicycle ergometer predictions of $\mathrm{VO}_{2}$ (max) were systematically lower than predictions based on the CHFT data (Table V), probably because of problems of quadriceps weakness when older subjects were exercised on the bicycle ergometer (Shephard et al, 1976). Nevertheless, there was a fair coefficient of correlation between the two sets of data $(r=0.72$ for 1,152 subjects). Cumming and Glenn (1977) compared the CHFT readings with the $\mathrm{VO}_{2}(\max )$ as predicted from a Bruce treadmill test time, and obtained almost identical mean values for the two procedures. However, perhaps because of the use of a treadmill test with a subjective end-point, the coefficients of correlation between the two sets of data were less than for the comparison with sub-maximal bicycle ergometry (Table VII). Jetté and his associates (1976) made a comparison between CHFT scores and direct treadmill measurements of $\dot{\mathrm{VO}}_{2}(\max )$ in 59 young adults (35 men, 24 women). The optimum equation for the determination of $\mathrm{VO}_{2}(\max )$ was:

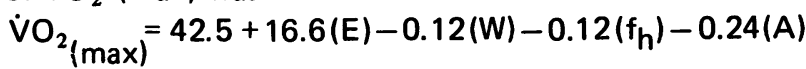

\section{TABLE IV}

Intended rhythm of Canadian Home Fitness Test, actual rhythm as measured on a high speed recorder, and rhythm reported in one criticism of test (Shephard, 1977c)

\begin{tabular}{|c|c|c|c|c|c|}
\hline \multirow[b]{2}{*}{$\begin{array}{l}\text { Intended } \\
\text { rhythm }\end{array}$} & \multicolumn{3}{|c|}{ WOMEN } & \multicolumn{2}{|l|}{ MEN } \\
\hline & $\begin{array}{l}\text { Actual } \\
\text { rhythm }\end{array}$ & $\begin{array}{l}\text { Reported } \\
\text { by Cumming } \\
\text { \& Glenn (1977) }\end{array}$ & $\begin{array}{l}\text { Intended } \\
\text { rhythm }\end{array}$ & $\begin{array}{l}\text { Actual } \\
\text { rhythm }\end{array}$ & $\begin{array}{l}\text { Reported } \\
\text { by Cumming } \\
\text { \& Glenn (1977) }\end{array}$ \\
\hline 66 & 66 & 72 & 66 & 66 & 66 \\
\hline 84 & 85 & 90 & 84 & 84.5 & 84 \\
\hline 102 & 102.5 & 108 & 102 & 102.5 & 102 \\
\hline 114 & 114 & 120 & 114 & 114 & 120 \\
\hline 120 & 121.5 & 126 & 132 & 133.5 & 138 \\
\hline \multirow[t]{2}{*}{132} & 134 & 138 & 144 & 144.7 & 150 \\
\hline & & & 156 & 159 & 168 \\
\hline
\end{tabular}


TABLE V

Departures from intended stepping rate observed in a group of young adults (Bonen et al, 1977)

$$
\begin{aligned}
& \text { Stepping bout \# } 1 \\
& \Delta \text { steps/min }
\end{aligned}
$$

$$
\begin{aligned}
& \text { Stepping bout \#2 } \\
& \Delta \text { steps/min }
\end{aligned}
$$

$\begin{array}{rrr}\text { Min 1 } & 1.4 \pm 2.0 & 1.4 \pm 2.2 \\ \text { Min 2 } & 0.4 \pm 2.0 & 0.5 \pm 1.8 \\ \text { Min 3 } & -1.0 \pm 2.0 & -0.2 \pm 1.8\end{array}$

\section{TABLE VI}

A comparison between the aerobic power predicted from a standard bicycle ergometer test and that predicted from the recovery pulse rate following the performance of the Canadian Home Fitness Test. Data for 1152 subjects tested in Saskatoon (Bailey et al, 1976).

$\begin{array}{lrlr}\begin{array}{l}\text { Age } \\ \text { (years) }\end{array} & \mathrm{N} & \begin{array}{l}\text { MEN } \\ \text { Bicycle }\end{array} & \text { Step } \\ & & & \\ \text { (ml } \mathrm{kg}^{-1} \mathrm{~min}^{-1} & \text { STDP) } & \\ 15-19 & 74 & 42.5 & 47.2 \\ 20-29 & 103 & 36.3 & 40.1 \\ 30-39 & 156 & 32.4 & 37.1 \\ 40-49 & 83 & 27.0 & 33.8 \\ 50-59 & 63 & 25.7 & 32.3 \\ 60-69 & 32 & 22.5 & 30.7 \\ & & & \\ & & \text { WOMEN } & \\ 15-19 & 120 & 33.7 & 39.2 \\ 20-29 & 136 & 30.6 & 37.3 \\ 30-39 & 149 & 28.1 & 34.6 \\ 40-49 & 92 & 24.4 & 31.8 \\ 50-59 & 88 & 21.9 & 31.2 \\ 60-69 & 55 & 18.9 & 30.2\end{array}$

TABLE VII

A comparison of predictions of maximum oxygen intake.

\begin{tabular}{|c|c|c|c|}
\hline Age & $\begin{array}{l}\dot{\mathrm{VO}}_{2}(\max ) \\
\text { CHFT }\end{array}$ & $\begin{array}{l}\mathrm{V}_{2}(\max ) \\
\text { Bruce prediction }\end{array}$ & $r$ \\
\hline $45-49$ & $37.8 \pm 7.6$ & $37.7 \pm 4.5$ & 0.22 \\
\hline $50-59$ & $34.2 \pm 8.6$ & $34.4 \pm 5.3$ & 0.46 \\
\hline $60-69$ & $33.4 \pm 12.9$ & $31.5 \pm 4.8$ & 0.62 \\
\hline
\end{tabular}
based on the Canadian Home Fitness Test and the duration of treadmill exercise (Bruce protocol Cumming and Glenn, 1977)

where $E$ was the average oxygen cost observed at a giver. rate of stepping ( $1 \mathrm{~min}^{-1}$ STPD), $W$ was the body mass $(\mathrm{kg}), f_{h}$ was the recovery heart rate, and $A$ was the age in years. Using the entire equation, the discrepancy betweeri the predicted result and the directly measured maximumio oxygen intake was $0.4 \pm 5.3 \mathrm{ml} \mathrm{kg}^{-1} \mathrm{~min}^{-1}$ in men, and $-0.1 \pm 3.3 \mathrm{ml} \mathrm{kg}^{-1} \mathrm{~min}^{-1}$ in women. Considering men anof women together, the coefficient of correlation between the two sets of data was 0.91. Further, the attained stepping rate and body mass alone yielded a correlation of 0.88 . Thus, the validity of the fitness categorisation was independent of the subject's ability to count the pulse rate accurately.

While the Jetté equation works well in a cross sectional sense, there is evidence that it is less effective than the Astrand nomogram in terms of detecting training response. In one large employee fitness programme, the Jetté formula indicated $\mathrm{VO}_{2}(\max \vec{E}$ gains of $5.7 \%$ in men and $4.4 \%$ in women, while thes gain indicated by the Åstrand nomogram were $13.2 \%$ in the men and $9.1 \%$ in the women (Shephard and Cox?़. 1980).

(3) Use of recovery heart rates. In home use of the test pulse counts are taken 5-15 sec after each bout of

\section{TABLE VIII}

\begin{tabular}{|c|c|c|c|c|}
\hline \multirow{3}{*}{$\begin{array}{l}\text { Age } \\
\text { (years) }\end{array}$} & \multicolumn{2}{|l|}{ Male Subjects } & \multicolumn{2}{|l|}{ Female Subjects } \\
\hline & $\begin{array}{l}\text { End-Exercise } \\
\text { Prediction } \\
\left(\mathrm{VO}_{2} \mathrm{ml} \cdot \mathrm{kg}^{-1} \mathrm{~min}^{-1}\right)\end{array}$ & $\begin{array}{l}\text { Early Recovery } \\
\text { Prediction } \\
\left(\mathrm{VO}_{2} \mathrm{ml} \cdot \mathrm{kg}^{-1} \mathrm{~min}^{-1}\right)\end{array}$ & $\begin{array}{l}\text { End-Exercise } \\
\text { Prediction } \\
\left(\mathrm{VO}_{2} \mathrm{ml} \cdot \mathrm{kg}^{-1} \min ^{-1}\right)\end{array}$ & $\begin{array}{l}\text { Early Recovery } \\
\text { Prediction } \\
\left(\mathrm{VO}_{2} \mathrm{ml} \cdot \mathrm{kg}^{-1} \mathrm{~min}^{-1}\right)\end{array}$ \\
\hline & STPD & STPD & STPD & STPD \\
\hline $15-19$ & 47.7 & 47.2 & 39.3 & 39.2 \\
\hline $20-29$ & 40.8 & 40.1 & 38.3 & 37.3 \\
\hline $30-39$ & 38.1 & 37.2 & 35.7 & 34.6 \\
\hline $40-49$ & 34.9 & 33.8 & 32.7 & 31.8 \\
\hline $50-59$ & 32.5 & 32.3 & 32.4 & 31.8 \\
\hline $60-69$ & 30.5 & 30.7 & 29.8 & 30.2 \\
\hline
\end{tabular}

Predictions of aerobic power based on electrocardiographic recordings of heart rate during the final 15 seconds of $\triangle$ exercise and 6-10 seconds after ceasing exercise. The close correspondence of the two sets of data establishes? the validity of early recovery pulse rates (Bailey et al, 1976). 
exercise. Cotton and Dill (1935) established many years ago that there was a close correlation between the exercise heart rate and pulse readings taken in the immediate recovery period. Recent research on the CHFT fully confirmed their observations.

In the Saskatoon study (Bailey et al, 1976), aerobic power was predicted from both the end-exercise heart rate and from a cardiotachometer estimate made 6-10 seconds after exercise. At all ages and in both sexes, the two sets of data yielded almost identical results (Table VIII); in young subjects, the rate was usually 1.2 beats/min higher in the recovery period, and in those who were older it was 1.2 beats/min lower. Cumming and Glenn (1977) tested older men, with similar results; they commented that the agreement of heart rates was equally close whether the count was based on the entire 5-15 second interval, the first five, or the last five beats.

(4) Palpation of exercise heart rate. The main limitation of the CHFT, well recognised in the original report, was errors arising in palpation of the heart rate during exercise (Bailey et al, 1976). In the Saskatoon trial, subjects were given no specific instruction in pulse counting, and relatively large errors were common (correlation between ECG/cardiotachometer reading and palpated rate $=0.50$ ). Nevertheless, it was argued that the average person could be trained to count his pulse, since the technique was used successfully by patients enrolled in cardiac rehabilitation programmes (Duncan et al, 1968). Jetté and his associates (1976) taught subjects to count their pulse rate "until they could do this accurately". Average readings for the measured e.c.g. and the palpated pulse were 154.1 \pm 22.2 and $147.0 \pm 23.2$ respectively, with a systematic difference of $7.0 \pm 5.6$ between the two sets of data (Jetté, 1975b; Jetté et al, 1976). Bailey and Mirwald (1975) found a similar difference between actual (134.7) and palpated (127.3) readings in 11-14 year old children who were used to counting their pulse (track and speed skating contestants). The coefficient of correlation between ECG and palpated values was 0.94 for these young athletes, but dropped to 0.76 when the pulse rate was determined by a partner, and to only 0.37 when tests were extended to children with little experience in pulse counting.

It is undoubtedly possible to find subjects who will make a bad job of pulse counting, as both Cumming and Glenn (1977) and Bonen et al (1977) have shown. However, it is a reasonable first assumption that those buying the Fit-Kit will be motivated to do the test as well as possible, and in such circumstances the estimates of error made by Jetté et al $(1975 b, 1976)$ and Bailey and Mirwald (1975) seem more realistic. In one recent evaluation (Shephard et al, 1979a), a hundred office workers were asked to read the cover of the Fit-Kit record carefully. They then carried out the test without further instruction. In this study, the palpated rate was matched against completed e.c.g. complexes for the same 10 second period (Table IX). As in much of the earlier work, there was a systematic error of about one count ( 6 beats $/ \mathrm{min}$ ) between the two readings; in addition, on average there was necessarily a half e.c.g. complex that was ignored. Thus in home use of the test it might be desirable to revise required fitness standards upwards by at least one pulse count per 10 second interval.

(5) Overall fitness levels. The best overall measure of validity of the test is perhaps the relationship between the overall fitness of the individual, and his CHFT score. In Saskatoon (Bailey et al, 1976), a good correlation was established between a simple five point rating of habitual activity and the test result (Table X). On the other hand, Bonen et al (1977) found relatively little difference of $\mathrm{VO}_{2}(\max )$ between young men attaining a minimum and a recommended level of fitness (respective values $44.4 \pm 3.6$ and $47.3 \pm 5.2 \mathrm{ml} \mathrm{kg}^{-1} \mathrm{~min}^{-1}$ STPD); this may reflect their use of a bicycle ergometer maximum test without objective criteria for an "oxygen plateau". Thacker (1977) himself counted the pulse rate for his subjects; using this approach, he obtained a correlation of 0.50 between CHFT scores and the response to one simple five point rating of habitual activity ("Heartbeat" Coronary Heart History, Loma Linde School of Health, California, which asks the question "How do you compare your physical activity with others your age?")

\section{TABLE IX}

Relationship of heart rate as measured by e.c.g. and palpated pulse rate during performance of the Canadian Home Fitness Test (Shephard et al, 1979)

ECG

heart rate

Rest

Stage 1

Stage 2

Stage 3
$75.8 \pm 10.6$

$125.5 \pm 18.4$

$142.8 \pm 17.2$

$148.7 \pm 16.1$
Palpated

pulse rate

$75.8 \pm 12.9$

$119.6 \pm 25.8$

$138.8 \pm 24.8$

$141.8 \pm 19.1$
$\Delta$

$0.1 \pm 11.3$

$5.9 \pm 20.1$

$4.0 \pm 18.1$

$6.9 \pm 20.6$
Correlation

0.549

0.632

0.682

0.327 
Investigators in the Canadian Public Health Association (Jetté, 1978) survey of 10,042 adults were asked whether the CHFT result as calculated from Jettés formula (1975b, 1976) was providing realistic data on the fitness of their subjects; 35 replied that it did, 4 that it did not, and 8 were uncertain. Those criticising the predictions gave somewhat contradictory assessments, as follows:

- underprediction in males $>50$ years who were in good condition

- underestimation in marathon runners and very well. trained people

- underestimation in women 20-30 years

- underestimation in obese subjects

- underestimation in heavy and older individuals

\section{PRACTICALITY OF THE TEST}

(1) Paramedical version. There is little question that the paramedical version of the test, with e.c.g. monitoring of heart rates, is a highly cost-effective method of mass fitness testing and even of electrocardiographic screening. In the original Saskatoon trial, up to 16 subjects were examined simultaneously, a 16-channel e.c.g. monitor being scanned continuously by an intensive-care nurse and a cardiology resident doctor with the assistance of five other paramedical personnel; the system was able to handle approximately 100 subjects per hour.

On the basis of this experience, the test is now being very widely used in Canada. It was one element of the occupational health project, first administered to 10,042 workers by the Canadian Public Health Association (Jetté, 1978), and continuing as Health and Welfare Canada's Standard Test of Occupational Fitness. It is one element of the Canada Health Survey, administered to a random sample of some 40,000 subjects. It is also an element of a motivational project sponsored by the Province of Ontario, where 7 mobile vans are testing upwards of 30,000 adults/year. We ourselves continue to use the test on a large scale, and have recently applied it to a controlled prospective study of industrial health, productivity and life satisfaction, with repeated testing of more than 1,000 employees at two large insurance companies (Shephard et al, 1979).

In all of these various applications, the test has given safe, consistent and reliable data.

(2) Home use. In the home setting, the prime purpose of the "Fit-Kit" is to motivate the population to greater physical activity. How well has this been accomplished? Recreation Canada (Publi-Media Inc., 1976) sponsored a test marketing of the CHFT in two medium-sized Canadian cities, one English-speaking and the other French-speaking, using English and French language versions of the test as appropriate. Questionnaires were circulated to 3,000 households receiving the Fit-Kit, and telephone interviews were conducted with 800 of this sample. Some $35 \%$ of respondents thought the test very good thing" and a further $55 \%$ qualified it as "a good thing". Indifferent or negative reactions (12\%) were somewhat more common in English than in French Canada. Over $78 \%$ of respondents read all the information on the jacket and listened to the recordings

\section{TABLE X}

Relationship between the aerobic power $\left(\mathrm{ml} \cdot \mathrm{kg}^{-1} \mathrm{~min}_{\vec{\Phi}}^{\vec{\Phi}}\right.$ STPD) as calculated from the Canadian Home Fitness Test and reported habitual activity (classed fro none $=1$, through occasional, regular, and very frequenif;; to specific sports training $=5$ ). Data for Saskatoon population (Jackson, 1975)

Aerobic Power of Men

Age $\quad\left(\mathrm{ml} \cdot \mathrm{kg}^{-1} \mathrm{~min}^{-1}\right.$ STPD)

(years) Reported habitual activity

$\begin{array}{lllllll} & 1 & 2 & 3 & 4 & 5 & \\ 15-19 & 48 & 31 & 38 & 52 & 51 & \varnothing \\ 20-29 & 41 & 39 & 40 & 44 & 48 & \\ 30-39 & 35 & 36 & 38 & 40 & 42 & \\ 40-49 & 33 & 34 & 34 & 41 & 39 & \\ 50-59 & 30 & 32 & 32 & 37 & - & \overline{0} \\ 60-69 & 26 & 33 & 30 & 29 & - & \varnothing \\ \text { All subjects } & 36 & 37 & 37 & 41 & 46\end{array}$

Aerobic Power of Women

\begin{tabular}{|c|c|c|c|c|c|}
\hline $15-19$ & 44 & 38 & 40 & 43 & 54 \\
\hline $20-29$ & 36 & 37 & 37 & 39 & - \\
\hline $30-39$ & 35 & 34 & 35 & 38 & 51 \\
\hline $40-49$ & 29 & 33 & 31 & 37 & - \\
\hline $50-59$ & 30 & 32 & 32 & 37 & - \\
\hline $60-69$ & 39 & 39 & 31 & 28 & - \\
\hline All subjects & 34 & 34 & 35 & 36 & 49 \\
\hline
\end{tabular}

$54 \%$ of respondents took the test, and a further 9 attempted to do so. Stated reasons for not taking the test included "lack of a record player" (38\%), "physicap disability" (9\%), "Lack of steps" $(2 \%)$ and "indifferenceN" $(51 \%)$. Of those taking the test, $96 \%$ encouraged othens to try it, the majority indicating use by 3 or more persons, while $90 \%$ also said they would take the tesf again. This suggests that the test succeeded in its objective of arousing interest in at least a half of the households receiving the kit. The instructions also seemed at an appropriate level, since $94 \%$ of those taking the test found the procedures simple or clea巴 The overall conclusion from the market survey was that $83 \%$ of respondents were positive, $10 \%$ had somg reservations as to the audio or visual aspects of the 
test, $5 \%$ were indifferent, and $2 \%$ were downright negative.

The accuracy of scores obtained in the house is more problematical. Some $54 \%$ of the sample reached the "recommended" level of fitness, 22\% the "minimum" level, and $6 \%$ the "undesirable" level, with $10 \%$ not completing the test and $8 \%$ unable to figure out their scores. This suggests that as in the initial validation trials, subjects may have systematically under-estimated their post-exercise pulse rates. A further factor is a selfselection of the fit as test participants. Subsequent evaluation of initial non-participants showed that these were substantially less fit than immediate test volunteers (Lauzon, 1978).

Reports from the Canadian Public Health Survey confirm the immediate motivational value of the procedure; test administrators indicated that the Fit-Kit made many subjects aware of their poor fitness level and gave them an incentive to improve, the test results providing a good basis for the discussion of such topics as cardio-respiratory fitness and maximal oxygen consumption.

As an incentive to practical application of the findings, the entire Fit-Kit package contains seven motivational items:

(i) "Health and Fitness" is a Canadian version of the popular booklet originally prepared by $\mathrm{Dr}$. P. O. Åstrand for a similar purpose in Sweden.

(ii) "R for physical activity" is a simple guide to the need for physical activity in weight control, flexibility, muscular endurance, cardio-pulmonary fitness and physical recreation.

(iii) "Fit-Tips" gives a series of rhythmic exercises designed to improve strength, endurance and flexibility in all major muscle groups.

(iv) A "walk-run distance calculator" (Jetté et al, 1975) enables a subject to calculate very simply how far he must go in 15 minutes, three times per week, in order to improve his fitness level. The basis of the prescription is exercise at $60 \%$ of the individual's $\mathrm{VO}_{2}(\max )$, the time to cover one mile $(Y, \min )$ being given (multiple $r=0.856$ ) by the formula:

$\mathrm{Y}=44.7-0.45\left(60 \% \mathrm{VO}_{2} \max , \mathrm{ml} \mathrm{kg}^{-1} \mathrm{~min}^{-1}\right)$

$$
-12.3 \text { (Height, } \mathrm{m} \text { ) }+0.015 \text { (Mass, } \mathrm{kg} \text { ) }
$$

(v) The "Fit-Kit Progress Chart" allows the individual to monitor the progress of his personal fitness programme.

(vi) An advanced test of fitness is provided for those who wish to progress beyond the "recommended" fitness level.

(vii) A series of four crests is provided to stick onto windbreakers or tracksuits for those who wish to advertise their participation in the CHFT programme.

\section{DISCUSSION}

Sackett (1975) proposed that four conditions be met before implementing a mass screening programme:

(i) the test must be reliable and valid.

(ii) health services must be capable of meeting the resultant demand for services.

(iii) compliance with the prescribed treatment must be high.

(iv) good must exceed evil.

The W.H.O. makes similar recommendations (Wilson and Junder). It is useful in conclusion to evaluate the CHFT against these four criteria (Lauzon, 1978).

(1) Reliability and validity. When administered by a paramedical professional, the test is both reliable and valid. It is quite practicable to test up to 100 subjects per hour, and the prediction of aerobic power obtained by the procedure seems at least as accurate as those yielded by other sub-maximal techniques. Indeed, it avoids the complication of quadriceps weakness that distorts bicycle ergometer readings in elderly subjects (Shephard, 1977a). The accuracy of the procedure undoubtedly diminishes when the test is carried out at home, although in this situation its primary role is that of motivator rather than precise predictor of $\mathrm{VO}_{2}$ (max). One estimate of the probable error of a self-administered test (Shephard et al, 1979a) summed pulse counting errors and individual differences of stepping rate and mechanical efficiency, for a total error of $10.3 \%$, accurate enough to (i) class 9 out of 10 individuals correctly in a 5-day classification of fitness, and (ii) to demonstrate a $25 \%$ gain of $\dot{\mathrm{VO}}_{2}(\max )$ with training in $\mathbf{9 7 . 5 \%}$ of subjects. Actual tests were carried out in an employee fitness programme; here, it is unlikely that everyone showed a training response, but nevertheless a gain of fitness category was seen in $83 \%$ of faithful adherents to the programme.

(2) Adequacy of health services. There seems little practical problem in providing personnel for exercise testing and fitness counselling. In the two months preceeding the Montreal Olympics, the Provincial Public Health Association of Quebec conducted over 70 CHFT leader clinics, training more than 2,000 health workers in the mechanics of group testing and fitness counselling. Equally, in English Canada, the Canadian Association for Health, Physical Education and Recreation has carried out 140 clinics for over 4,000 fitness leaders.

The main source of continuing practical concern is the disposition of abnormal electrocardiograms. The paramedical worker normally uses the e.c.g. to count the heart rate, but if he has some experience in electrocardiography he cannot ethically ignore a doubtful 
waveform. However, if all records under suspicion are referred to a cardiologist for examination, with possible re-evaluation of the patient by a laboratory stress test, the cost could be enormous. Possible solutions are (i) to use a cardiology resident to monitor 16 e.c.g.'s simultaneously (as in the Saskatoon study), or to screen waveforms for a small fee (as in the University of Toronto study) or (ii) to amend legislation, permitting the training of both paramedical workers and interested family physicians in the interpretation of exercise e.c.g.'s (as in the American College of Sports Medicine programme for the certification of exercise class leaders and exercise technicians). One recent study showed a very close correspondence of exercise e.c.g. interpretation between a trained technician and a cardiologist (Shephard and Cox, 1980).

(3) Compliance. Exercise programmes are generally plagued by a high drop-out rate (Massie and Shephard, 1976; Sidney and Shephard, 1976) and the problem of persuading subjects to persist with exercise prescriptions in undoubtedly the biggest challenge to the Fit-Kit programme.

Meyer and Henderson (1974) have reported encouraging results from behavioural modification approaches to CHD risk factor reduction, and there may be scope for similar techniques in exercise promotion. Jackson's study of Participation Saskatoon, a community fitness awareness programme, certainly in dicates that the technology is available to improw exercise compliance (Jackson, 1975).

(4) Good and evil. There seems little cause for concero regarding the safety of the test, although an ethical issue could be raised if people are made anxious about the need for exercise, and yet fail to comply with the prescribed regimen.

A number of epidemiological studies point to th $\vec{\oplus}$ possible health benefits of increased physical activity, but none are conclusive, since the proof is complicated by initial self-selection of the exercise regimen. On the other hand, there is little reason to suppose thas moderate exercise is harmful to health, and many authors have concluded that the beneficial effect of mood is in itself sufficient justification for advocating an increase of physical activity.

Certainly, as stated by Lauzon (1978), there is reaso to suspect that good exceeds evil, with little evidence favouring the converse hypothesis.

\section{ACKNOWLEDGEMENT}

This research has been supported in part by a grant from the Fitness and Amateur Sport Branch, Health an Welfare Canada.

\section{REFERENCES}

American College of Sports Medicine, 1975. Guidelines for graded exercise testing and exercise prescriptiog. Philadelphia: Lea \& Febiger.

Åstrand, 1., 1960. "Aerobic work capacity in men and women, with special reference to age." Acta Physiol.Scand. 49. Suppl. 169: 45.

Bailey, D. A. and Mirwald, R. L, 1975. "A children's test of fitness." Report to Action; British Columbia.

Bailey, D. A., Shephard, R. J. and Mirwald, R. L., 1976. "Validation of a self-administered home test of cardio respiratory fitness." Canad.J.Appl.Sports Sci. 1: 67-78.

Bailey, D. A., Shephard, R. J., Mirwald, R. L. and Weese, C., 1974. "A current view of Canadian cardio-respirator fitness." Canad.Med.Assoc.J. 111: 25-30.

Bonen, A., Gardner, J., Primrose, J., Quigley, R. and Smith, D., 1977. “An evaluation of the Canadian Home Fitnes Test." Carad.J.Appl.Sports Sci. 2: 133-136.

Chisholm, D. M., Collis, M. L., Kulak, L. L. et al, 1975. “Physical activity readiness." Brit.Col.Med.J. 17: (iif 375-385.

Cooper, K. H., 1968. Aerobics. Evans, New York.

Cooper, K. H., 1970. "Guidelines in the management of the exercising patient." J.Amer.Med.Assoc. 211: 1663-1667잉

Cotton, F. and Dill, D. B., 1935. "On the relationship between the heart rate during exercise and that of the immediate post-exercise period." Amer.J.Physiol. 111: 554-558. 
Cox, M. and Shephard, R. J., 1979. "Employee fitness, absenteeism and job satisfaction." Med.Sci.Sport 11: 105.

Cumming, G. R. and Glenn, J., 1977. "Evaluation of the Canadian Home Fitness Test in middle-aged men." Canad.Med. Assoc.J. 117: 346-349.

Duncan, W. R., Ross, W. D. and Banister, E. W., 1968. "Heart rate monitoring as a guide to the intensity of an exercise programme." Brit.Columbia Med.J. 10 (8).

Gardner, G. W., Danks, D. L. and Scharfsien, L., 1979. "Use of carotid pulse for heart rate monitoring." Med.Sci.Sport 11: 111.

Health and Welfare, Canada, 1979. Standard Test of Occupational Fitness. Ottawa, Ontario.

Jackson, J. J., 1975. "Diffusion of an innovation: An exploratory study on the consequences of Sport Participation Canada's campaign at Saskatoon." PhD Dissertation, University of Alberta, Edmonton, Alberta.

Jetté, M., 1975. "An exercise prescription program for use in conjunction with the Canadian Home Fitness Test." Canad.J.Publ. Health 66: 461-464.

Jetté, M., 1975. "The Canadian Home Fitness Test as a predictor of maximal oxygen consumption." Report to Recreation Canada.

Jetté, M., 1978. "Technical report. Standardized test of fitness in occupational health." Fitness and Amateur Sport, Dept. of Natural Health and Welfare, Ottawa.

Jetté, M., Campbell, J., Mongeon, J. and Routhier, R., 1975. "The energy requirements of the Canadian Home Fitness Test." Report to Recreation Canada.

Jetté, M., Campbell, J., Mongeon, J. and Routhier, R., 1976. "The Canadian Home Fitness Test as a predictor of aerobic capacity." Canad.Med.Assoc.J. 114: 680-682.

Jetté, M., Thoden, J. S. and Gauthier, R., 1975. "Aerobic exercise prescription intensity in terms of maximal working capacity." Canad.J.Publ. Health 66: 465-467.

Kudo, E., 1974. "On the use of music in the learning and teaching of gymnastic exercises." Paper presented at the International Congress on Physical Education for Girls and Women. Helsinki, Finland.

Lauzon, R. R. J., 1978. "The Canadian Home Fitness Test in the Health Environment." pp. 329-334. In: Physical Fitness Assessment. Principles, practice and application. Ed.: R. J. Shephard and H. Lavallée. C. C. Thomas, Springfield, IIlinois.

Massie, J. F. and Shephard, R. J., 1971. "Physiological and psychological effects of training." Med.Sci.Sports 3: 110-117.

Meyer, A. and Henderson, J. 1974. "Multiple risk-factor reduction in the prevention of cardiovascular disease." Prev.Med. 3: 225-226.

Orban, W. R., 1974. Ed: Proceedings of the National Conference on Fitness and Health. Ottawa: Information Canada.

Publi-Media, Inc., 1975. The Canadian Home Fitness Test - test market report to Recreation Canada.

Sackett, D. L., 1975. Workshop lecture. Halifax, Nova Scotia - Division of Family Medicine, Dalhousie University. (Cited by Lauzon, 1978).

Shephard, D. A. E., 1976. "Home testing of fitness of Canadians." Canad.Med.Assoc.J. 114: 662-663.

Shephard, R. J., 1967. "The prediction of 'maximal' oxygen consumption using a new progressive step test." Ergonomics 10: 1-15. 
Shephard, R. J., 1970. "Computer programmes for solution of the Åstrand nomogram." J.Sports Med.Phys.Fitnes 10: 206-210.

Shephard, R. J., 1974. "Sudden death - a significant hazard of exercise?" Brit.J.Sports Med. 8: 101-110.

Shephard, R. J., 1977a. Endurance Fitness (2nd Ed.). University of Toronto Press, Toronto.

Shephard, R. J., 1976. "Coronary artery disease - the magnitude of the problem." pp. 1-14. In: Proceedings oळ International Symposium on Exercise and Coronary Artery Disease. Ed. T. Kavanagh. Toronto: Toronto Rehabilitation Centre.

Shephard, R. J., 1977b. “Do risks of exercise justify costly caution?" Physician and Sports Med. 5 (2): 55-65.

Shephard, R. J., 1977c. "Letter to Editor." Canad.Med.Assoc.J. 117.

Shephard, R. J., Allen, C., Benade, A. J., Davies, C. T. M., diPrampero, P. E., Hedman, R., Merriman, J. E., Myhre, K. and Simmons, R., 1968. "The maximum oxygen intake - an international reference standard of cardio-respirator $\hat{\mathrm{U}}$ fitness." Bull.W.H.O. 38: 757-764.

Shephard, R. J., Bailey, D. A. and Mirwald, R. L., 1976. Development of the Canadian Home Fitness Test. Canad.Med $\vec{\overrightarrow{ }}$ Assoc.J. 114: 675-679.

Shephard, R. J., Cox, M., Corey, P. and Smyth, R., 1979a. "Some factors affecting the accuracy of Canadian Home Fitness Test Scores." Canad.J.Appl.Sports Sci. In Press.

Shephard, R. J., Cox, M. and Simpner, K., 1979b. "An analysis of PAR-Q responses in an office population." Canad.J? Appl.Sports Sci. In Press.

Shephard, R. J. and Cox, 1980. "Changes of Canadian Home Fitness Test Scores over an employee fitness programme." Canad.J.Appl.Sports Sci. In Press.

Sidney, K. H. and Shephard, R. J., 1976. "Attitudes towards health and physical activity in the elderly." Effects of a physical training programme. Med.Sci.Sports 8: 246-252.

Thacker, J., 1977. "A project to study the relationship between questions about physical activity and fitness levels on the Canadian Home Fitness Test." MSc Thesis, Temple University, Philadelphia.

Weiner, J. S. and Lourie, J. A., 1969. Human Biology. A guide to field methods. Blackwell Scientific Publications Oxford and Edinburgh.

Wilson, J. M. G. and Junder, G., 1968. Principles and Practice of Screening for Disease. Public Health Papers No. 34@ 